\title{
PAY SATISFACTION AND ORGANISATIONAL TRUST: AN IMPORTANCE-PERFORMANCE MAP ANALYSIS
}

\author{
Gabriel C. W. Gim ${ }^{a^{*}}$ and Wen-Sing Cheah ${ }^{\mathrm{b}}$ \\ ${ }^{a}$ Han Chiang University College of Communication, Penang, Malaysia \\ ${ }^{b}$ Wawasan Open University, Penang, Malaysia \\ *gabrielgim83@gmail.com
}

\begin{abstract}
Using social exchange theory and equity theory, this paper examined the relationship between the four dimensions of pay satisfaction and organisational trust among Malaysian employees. The four dimensions of pay satisfaction are pay benefit satisfaction, pay level satisfaction, pay raise satisfaction, and pay structure and administration satisfaction. Questionnaires were distributed to Malaysians working in several industries. Partial least squares structural equation modeling (PLS-SEM) was used to assess both the measurement and structural model. Results from the structural model revealed that pay benefit satisfaction, pay raise satisfaction, and pay structure and administration satisfaction were positively related to organisational trust. To complement the standard structural model assessment, robustness checks were performed on the structural model in terms of non-linear effects, endogeneity, and unobserved heterogeneity. The checks concluded that there were no issues with regards to nonlinear effects and unobserved heterogeneity. However, the endogeneity test indicated that pay structure and administration satisfaction could be endogenous. Importance-performance map analysis (IPMA) was also performed to gauge the importance and performance of each dimension of pay satisfaction against organisational trust. The IPMA results revealed that pay structure and administration satisfaction was the most important factor yet it attained the lowest score on performance indicating that organisations in Malaysia should make an improvement to their pay structure and administration satisfaction.
\end{abstract}

Keywords: pay benefit satisfaction, pay level satisfaction, pay structure satisfaction, organizational trust

\section{INTRODUCTION}

Employees in Malaysia are paid lower compared to other developed countries such as United Kingdom, Australia, Germany, and Singapore, even after accounting for a similar rate of productivity (Bank Negara Malaysia, 2018). The abundance of low-skilled foreign labour not only depresses the salary of the locals, it also impedes the country's progress towards a high-productivity nation (Bank Negara Malaysia, 2018). According to Employee Job Happiness Index 2017, one in three Malaysians wanted a pay rise (Jobstreet.com, 2017) indicating these group of Malaysians were not happy with their current pay. Furthermore, Malaysians have rated pay satisfaction as the most important determinant of satisfaction at the workplace above advancement opportunities and interesting work (Mahalingam, 2013).

Employees in Malaysia valued trust as well. Based on a PwC survey among women, there were calls for greater transparency at the workplace because the respondents believe that their employers were 
not truthful on career development and promotion (Benjamin, 2018). If employers keep their promises regarding work matters, employees are more likely to trust them (Lambert, Hogan, Barton-Bellessa, \& Jiang, 2012)

Labour cost usually represents the biggest expense of an organisation (Jawahar \& Stone, 2011) and employers may spend up to 70 to 80 percent of their budget on salary alone (Singh \& Loncar, 2010). It is a challenge to organisations to retain the best talent and yet to minimise such cost. Therefore, it is important to understand the importance of each dimension of pay satisfaction so that employers could pay attention to the most effective dimension to elicit higher trust from employees.

The objectives of this research are twofold. First, it aimed to investigate the impacts of each the four dimensions of pay satisfaction on organisational trust, which helps to add to the growing literature on pay satisfaction. Secondly, it aimed to investigate the importance and performance of the four dimensions of pay satisfaction against trust from the perspective of the importance-performance map analysis (IPMA). The IPMA is expected to help practitioners in identifying the role each dimension of pay satisfaction plays in improving organisational trust.

To overcome the limitations of previous studies which examined pay satisfaction as uni-dimensional (Jung \& Yoon, 2015), this study examined the multi-dimensional factors of pay satisfaction. Despite the four factors of pay satisfaction have been examined in relation to various organisational outcomes such as work-to-family conflict (Khokhar \& Zia-ur-Rehman, 2014), work engagement, and turnover intention (Jung \& Yoon, 2015); studies examining the relationship between all four dimensions of pay satisfaction and organisational trust remain scarce.

Following from the introduction, this paper next introduces the underlying theory followed by the development of the hypotheses. Subsequently, the research methods were discussed in conducting this research. Following from there, the analysis and discussion were discussed in detail, which include the theoretical implications, practical implications, and limitations and future suggestions.

\section{UNDERLYING THEORIES}

Two underlying theories help to pin the model and they are the social exchange theory and equity theory. Social exchange theory refers to a voluntary mutual beneficial exchange between two parties, usually between an employee and an employer (Blau, 1964). The mutual relationship and maintenance of trust can be explained through the social exchange theory (Blau, 1964). Trust is an important component in the social exchange theory and the level of trust in organisations is an indicator of the quality of relationship between an employee and an employer (Jiang, Gollan, \& Brooks, 2015). The level of trust can be built through constant obligation fulfilment and the expansion of exchange (Blau, 1964). In short, organisations who treat their employees well will be repaid with higher level of trust (Kim, 2019).

Based on the explanation of the social exchange theory, employers can therefore build trust by paying their employees satisfactorily because employees who are paid satisfactorily will reciprocate by trusting their employers. Employees who are satisfied with their pay will trust the organisation; otherwise, employees will not trust the organisation if employers lack the generosity in rewarding employees.

Complementing the social exchange theory in this study is the equity theory. Equity theory refers to the situation where an employee compares their outcome/input ratio with their colleagues and even with other employees outside their organisation (Adams, 1965; Till \& Karren, 2011, Wang, Hu, Mao, \& Liu, 2019). How one is satisfied with their salary depends on how much they earn compared to others (Till \& Karren, 2011). An employee who perceive their salary as fair will be satisfied with their salary. Cloutier, Morin, and Renaud (2013) demonstrated that pay satisfaction is dependent on meeting the employees' expectations based on their contributions to the organisation. Based on equity theory, organisations who take steps to improve the pay satisfaction of employees are more likely to see higher motivation among their employees (Zheng, Wang, and Song, 2014). Applications of equity theory is several researches on pay satisfaction have shown the saliency of fairness in awarding salary 
(Cloutier et al., 2013; Till \& Karren, 2011). Therefore, it is important for organisations to demonstrate fair salary is being awarded to employees in order to generate positive outcomes in organisations including organisational trust.

\section{HYPOTHESIS DEVELOPMENT}

\section{Pay satisfaction and organisational trust}

Pay satisfaction refers to the strength of positive feeling towards the monetary rewards an employee receives from their workplace (Campbell \& Im, 2019; Miceli \& Lane, 1991). Pay satisfaction has been shown to be positively related to job satisfaction, organisational commitment, and organisational citizenship behaviour towards the organisation (Chan \& Ao, 2018; Johnson \& Lake, 2019). Pay satisfaction has also been shown to be negatively related to job burnout and turnover intention (Chan \& Ao, 2018; Wang et al., 2019).

Recognising that pay satisfaction is multidimensional (Heneman \& Schwab, 1985; Tekleab, Bartol, \& Liu, 2005) and responding to the call to use the multidimensional factors of pay satisfaction (Treuren \& Frankish, 2014), we examined the four dimensions of pay satisfaction in relation to organisational trust. The four dimensions of pay satisfaction are pay benefit satisfaction, pay level satisfaction, pay raise satisfaction, and pay structure and administration satisfaction.

Pay benefit refers to the individual's indirect pay such as annual leave, sick leave, insurance, and medical benefits; pay level refers to the individual's current salary; pay raise refers to changes to the individual's current salary; and pay structure and administration refers to pay rates at each successive level in the organisational hierarchy and the procedures involved in determining salary for employees (Heneman \& Schwab, 1985; Williams, McDaniel, \& Ford, 2007).

Both pay level satisfaction and pay benefit satisfaction mirror distributive justice whereas both pay raise satisfaction and pay structure and administration satisfaction mirror procedural justice (Bhave, Kramer, \& Glomb, 2013). Furthermore, researchers (Jawahar \& Stone, 2011; Folger \& Konovsky, 1989; Tekleab et al., 2005) have showed that distributive justice was related to pay level satisfaction whereas procedural justice was related to pay benefit satisfaction, pay raise satisfaction, and pay structure and administration satisfaction. Researchers (Jawahar \& Stone, 2011; Till \& Karren, 2011) have also demonstrated that informational justice was related to pay level satisfaction, pay raise satisfaction, and pay structure and administration satisfaction.

Robinson (1996) defined trust as "one's expectations, assumptions, or beliefs about the likelihood that another's future actions will be beneficial, favourable, or at least not detrimental to one's interests" (p. 576). Organisational trust is a cognitive attitude developed by judging the integrity of the employer (Robinson, 1996). Consequently, employees conclude their judgement by checking the perceived consistency between the words and actions of the employer (Robinson, 1996). Trust is an essential ingredient to maintain a healthy social relationship and the lack of trust can undermine that relationship (Robinson, 1996). Looking at organisational trust specifically, employees evaluate the organisation by monitoring the roles, rules, and structured relations within the organisation to determine whether to trust the organisation or not (Ahteela \& Vanhala, 2018). Additionally, organisational trust is a psychological state based on perception rather than reality (Lambert et al., 2012). Therefore, it is important for organisations to create a positive perception of their organisational settings to build higher level of trust from employees.

A meta-analysis study by Williams et al. (2007) indicated that all dimensions of pay satisfaction were positively related to organisational commitment and negatively related to turnover intention. Ren, Fang, and Yang (2017) showed that pay level satisfaction was positively related to job satisfaction, discretionary effort, and interpersonal helping. Tekleab et al. (2005) also showed that pay raise satisfaction is related to turnover intention and actual turnover. Khokhar and Zia-ur-Rehman (2014) found that pay level satisfaction, pay benefit satisfaction, and pay structure and administration satisfaction were negatively related to work-to-family conflict. Moon, Cho, Lee, and Oah (2014) found that both pay system satisfaction and pay benefit satisfaction were positively related to trust in management. Jung and Yoon (2015) found that all four dimensions of pay satisfaction were positively 
related to work engagement and negatively related to turnover intention. The above studies indicated that pay satisfaction brought positive organisational outcomes.

Jiang et al. (2015) found that distributive justice and procedural justice were positively related to organisational trust. Ogbonnaya and Daniels (2017) found that performance-related pay was positively related to trust in management. The above studies indicated that positive perception regarding pay and fairness were related to higher trust.

Both social exchange theory and equity theory help to explain that employees who are treated well by their employers will reciprocate in good faith to their employers. In this study, it is expected that employees who are satisfied with their benefit, pay, pay raise, and pay structure and administration will reciprocate by having higher trust on the organisations.

With the above justification using empirical literature and guided by both social exchange theory and equity theory, we hypothesised the research model (as depicted in Figure 1 below) as follows:

$\mathrm{H}_{1}$ : Pay benefit satisfaction is positively related to organisational trust.

$\mathrm{H}_{2}$ : Pay level satisfaction is positively related to organisational trust.

$\mathrm{H}_{3}$ : Pay raise satisfaction is positively related to organisational trust.

$\mathrm{H}_{4}$ : Pay structure and administration satisfaction is positively related to organisational trust.

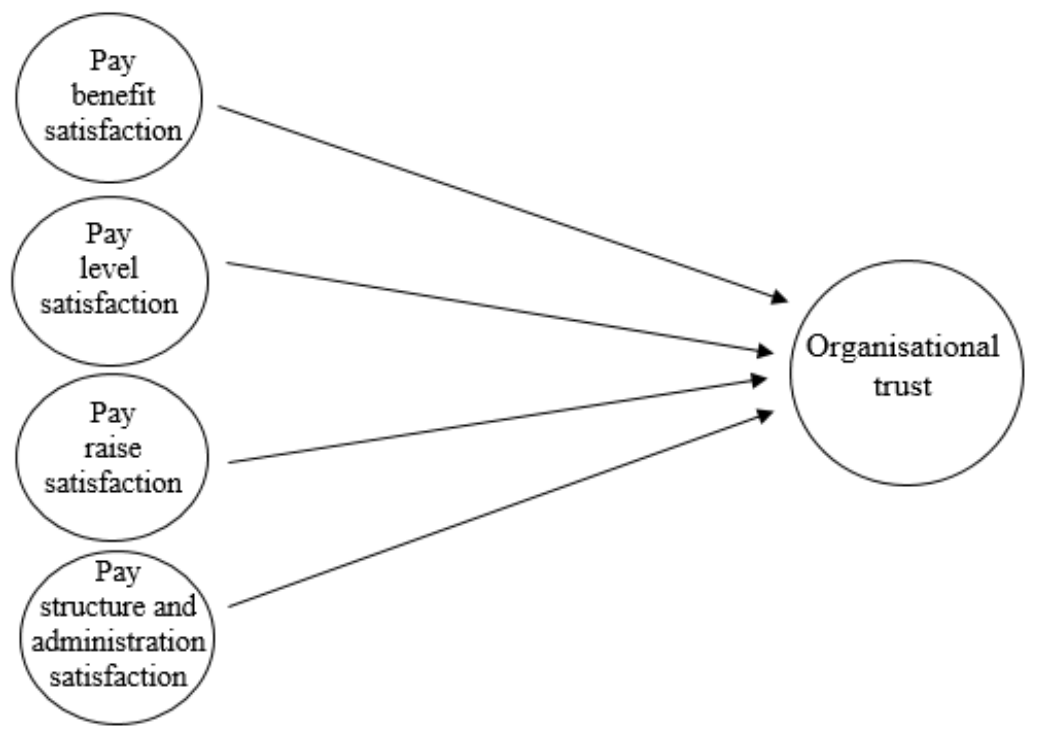

Figure 1: Research model

\section{METHODOLOGY}

Based on the G*Power software (Faul, Erdfelder, Buchner, \& Lang, 2009), the minimum sample size computed was 85 respondents with the assumption of 0.15 effect size, $80 \%$ power and four independent variables. Thus, we distributed as many as 500 questionnaires using snowball sampling through known acquaintances who are fully employed in Malaysia to ensure at least 85 respondents could be collected. First of all, a total of 25 known acquaintances who are working full time at various industries were contacted by the researchers. Each of them was given 20 copies of the questionnaire for themselves to fill up and to be distributed to their known recommended respondents. The eligibility of the respondent was screened through a screening question asking them whether they are a full time or part time employee. If the answer is no, the questionnaire will be discarded.

A total of 354 questionnaires were received and those with straight lining responses, and excessive missing data were discarded. After removing those undesired responses, the sample comprises a total 
of 306 respondents giving a final response rate of $61.2 \%$. The majority of the respondents are female $(51.6 \%)$, Chinese (71.6\%), not married (57.8\%), diploma holders $(32.7 \%)$, have been working between one to two years at their organisations (36.3\%), and are earning between RM2,001 and RM4,000 $(46.4 \%)$.

\section{Measurement}

We measured the four dimensions of pay satisfaction with 18 items adapted from Heneman and Schwab (1985) on a 5-point scale ranging from 1 (very dissatisfied) to 5 (very satisfied). An example of a pay benefit satisfaction item is "My benefit package". An example of a pay level satisfaction item is "My take-home salary". An example of a pay raise satisfaction item is "My most recent raise". An example of a pay structure and administration item is "The company's salary structure".

We measured organisational trust with seven items adapted from Robinson (1996) on a seven-point scale ranging from 1 (strongly disagree) to 7 (strongly agree). Example of the items include "I believe my employer has high integrity" and "My employer is not always honest and truthful".

The full set of measurement items for pay satisfaction and trust are shown in the Appendix below. Other than the study variables, we also sought the profiles of respondents such as age, gender, race, marital status, educational level, years of working, and monthly income.

\section{RESULTS}

We analysed the collected data based on partial least squares-structural equation modelling (PLSSEM) using SmartPLS version 3.2.7 (Ringle, Wende, \& Becker, 2015). We also relied on Statistical Package for Social Science (SPSS) and R software (R Core Team, 2019) for data input as well as to check the robustness of the structural model. Before proceeding to the PLS-SEM analysis, data transformation and data screening were performed first. As required of PLS-SEM analysis, we assessed the measurement model first prior to assessing the structural model.

\section{Data transformation and screening}

The collected data were subjected to both data transformation and data screening. First of all, reverse coded items were transformed by reversing them prior to any analysis. There were three reversed coded items in the organisational trust variable which were then reversed prior to any analysis.

Secondly, data screening was performed to assess missing data, outliers, and common method bias. Responses with minimal missing values were replaced using expectation maximisation in SPSS. To assess outliers, regression was performed in SPSS to obtain the standardised residuals through the case wise diagnostics table. There were no standardised residuals which were beyond +3.3 and -3.3 (Tabachnick \& Fidell, 2013). Therefore, there were no outliers in this study. To assess common method bias, Harman's single factor test was performed in SPSS. The first eigenvalues obtained was $34.40 \%$, which was lower than the $40 \%$ threshold as recommended by Babin, Griffin, and Hair (2016). Therefore, common method bias was not an issue in this study.

\section{Measurement model}

We assessed the measurement model by inspecting the convergent validity, discriminant validity, and the internal consistency reliability.

\section{Convergent validity}

We assessed convergent validity by inspecting the factor loadings, average variance extracted (AVE), and the composite reliability. We deleted items OT3, OT5, and OT7 because the factor loadings were below 0.40 . As a consequence of the deletion, it pushed the AVE of the organisational trust construct to above the 0.50 threshold. The item wordings for OT3, OT5, and OT7 are shown in the appendix and these items were all reversed-coded negatively worded statements. It therefore implied that negatively worded items might have caused confusion among the respondents and hence, the low 
factor loadings. Van Sonderen, Sanderman, and Coyne (2013) advocated that all questionnaire items should be worded in the same direction because they found that even having negatively worded items did not prevent acquiescence bias.

Although some other items contained loadings between 0.40 and 0.70 , they were not deleted because the AVEs were already above 0.50 (Hair, Hult, Ringle, \& Sarstedt, 2017). All factor loadings were at least above 0.40; AVEs were above 0.50, and the composite reliabilities were above 0.70. As a result, the measurement model was convergently valid.

\section{Discriminant validity}

We assessed discriminant validity by inspecting the outer loadings, Fornell-Larcker criterion, and the heterotrait-monotrait (HTMT) ratio of correlations. Firstly, there were no cross-loadings. Secondly, the square root of the AVEs were above the correlations among the variables. Thirdly, the HTMT ratios of correlations were below the recommended threshold of 0.90 (Gold, Malhotra, \& Segars, 2001). However, the two-tailed bias-corrected bootstrap confidence interval of $95 \%$ with regards to the relationship between among the four dimensions of pay satisfaction showed that they exceeded the threshold of 0.90. Therefore, PLS1, PRS4, and PSS1 were deleted in order to establish discriminant validity. Consequently, after the deletion of those items, all of the upper limit of the confidence interval was below the threshold of 0.90. As a result, the model was shown to be discriminately valid.

Due to the additional deletion of items, convergent validity was re-assessed to ensure that the AVE, factor loadings, and composite reliabilities were still above the required thresholds. Table 1 displays the factor loadings, AVEs, and composite reliabilities for all constructs and they were still above the recommended thresholds. The Fornell-Larcker criterion was also re-assessed and the AVEs were still above the correlations among the variables as shown in Table 2 . The mean and standard deviation of each variable derived from the latent variable scores are also shown in Table 2. The HTMT ratios of correlations were inspected again and they were still below the recommended threshold of 0.90 as shown in Table 3.

\section{Internal consistency reliability}

We inspected the composite reliability for all constructs to ensure it is at least above 0.70 (Hair et al., 2017). As shown in Table 1, the composite reliability for all constructs were well above 0.70; thus, showing that all the constructs were reliable.

Table 1: Convergent validity assessment

\begin{tabular}{|c|c|c|c|c|}
\hline Construct & Item & Loading & $\begin{array}{l}\text { Composite } \\
\text { reliability }\end{array}$ & AVE \\
\hline \multirow{4}{*}{$\begin{array}{l}\text { Pay benefit } \\
\text { satisfaction }\end{array}$} & PBS1 & 0.879 & 0.905 & 0.703 \\
\hline & $\mathrm{PBS} 2$ & 0.842 & & \\
\hline & PBS3 & 0.820 & & \\
\hline & $\mathrm{PBS}_{4}$ & 0.812 & & \\
\hline \multirow[t]{3}{*}{ Pay level } & $\mathrm{PLS} 2$ & 0.880 & 0.889 & 0.729 \\
\hline & PLS3 & 0.881 & & \\
\hline & PLS4 & 0.797 & & \\
\hline \multirow{3}{*}{$\begin{array}{l}\text { Pay raise } \\
\text { satisfaction }\end{array}$} & PRS1 & 0.894 & 0.811 & 0.593 \\
\hline & $\mathrm{PRS} 2$ & 0.649 & & \\
\hline & PRS3 & 0.747 & & \\
\hline \multirow{5}{*}{$\begin{array}{l}\text { Pay structure and } \\
\text { administration } \\
\text { satisfaction }\end{array}$} & $\mathrm{PSS}_{2}$ & 0.678 & 0.854 & 0.540 \\
\hline & PSS3 & 0.769 & & \\
\hline & PSS4 & 0.708 & & \\
\hline & PSS5 & 0.734 & & \\
\hline & PSS6 & 0.781 & & \\
\hline \multirow{4}{*}{$\begin{array}{l}\text { Organisational } \\
\text { trust }\end{array}$} & OT1 & 0.840 & 0.88 & 0.647 \\
\hline & $\mathrm{OT} 2$ & 0.817 & & \\
\hline & OT4 & 0.788 & & \\
\hline & OT6 & 0.771 & & \\
\hline
\end{tabular}


Table 2: Mean, standard deviation, and latent variable correlation

\begin{tabular}{lccccccc}
\hline & $\boldsymbol{M}$ & $\boldsymbol{S D}$ & PBS & PLS & PRS & PSS & OT \\
\hline PBS & 3.3222 & 0.7498 & $\mathbf{0 . 8 3 9}$ & & & & \\
PLS & 3.1907 & 0.7933 & 0.534 & $\mathbf{0 . 8 5 4}$ & & & \\
PRS & 3.2655 & 0.7071 & 0.619 & 0.556 & $\mathbf{0 . 7 7 0}$ & & \\
PSS & 3.3585 & 0.6048 & 0.593 & 0.481 & 0.564 & $\mathbf{0 . 7 3 5}$ & $\mathbf{0 . 8 0 5}$ \\
OT & 4.7926 & 1.0488 & 0.433 & 0.290 & 0.461 & 0.476 &
\end{tabular}

Note: The bolded diagonals represent the square roots of the AVE while the other entries below the square roots of the AVE represent the latent variable correlations. PBS = Pay benefit satisfaction; PLS = pay level satisfaction, $\mathrm{PSR}=$ pay raise satisfaction, $\mathrm{PSS}=$ Pay structure and administration satisfaction, $\mathrm{OT}=$ organisational trust

Table 3: Heterotrait-monotrait ratio of correlations

\begin{tabular}{lccccc}
\hline & PBS & PLS & PRS & PSS & OT \\
\hline PBS & & & & & \\
PLS & 0.610 & & & & \\
PRS & 0.786 & 0.712 & & & \\
PSS & 0.729 & 0.575 & 0.794 & & \\
OT & 0.503 & 0.341 & 0.578 & 0.5849 & \\
\hline
\end{tabular}

\section{STRUCTURAL MODEL ASSESSMENT}

Consequently, after the measurement model assessment, the structural model was assessed. The structural model assessment entails checking the collinearity, path coefficients, coefficient of determination, effect size, and predictive relevance.

The variance inflation factor (VIF) values for all independent variables were below 5 ; thus, denoting that there were no issues of collinearity.

Next, we checked the path coefficients of each relationship. As shown in Table 4, pay benefit satisfaction $(\beta=0.148, \mathrm{p}<0.05)$, pay raise satisfaction $(\beta=0.245, \mathrm{p}<0.001)$, pay structure and administration satisfaction $(\beta=0.278, p<0.001)$ were found to be positively related to organisational trust; thus giving support to $\mathrm{H} 1, \mathrm{H} 3$, and $\mathrm{H} 4$. However, pay level satisfaction $(\beta=-0.059, \mathrm{p}>0.05)$ was not found to be related to organisational trust; thus, $\mathrm{H} 2$ was not supported.

Regarding effect size, only pay raise satisfaction $(\mathrm{f} 2=0.043)$ and pay structure and administration satisfaction (f2 $=0.063$ ) exhibited small effect sizes on organisational trust because they exceeded the minimum threshold of 0.02. Both pay level satisfaction and pay benefit satisfaction did not meet the minimum threshold for its effect size. Hence, only pay raise satisfaction and pay structure and administration satisfaction demonstrated practical utility in their effects against organisational trust.

Table 4: Hypotheses testing

\begin{tabular}{lcccccccc}
\hline Hypotheses & Beta & $\begin{array}{c}\text { Std } \\
\text { error }\end{array}$ & t-value & $\begin{array}{c}\text { BCa CI } \\
\text { lower } \\
\text { limit }\end{array}$ & $\begin{array}{c}\text { BCa CI } \\
\text { upper } \\
\text { limit }\end{array}$ & $\begin{array}{c}\boldsymbol{f}^{2} \\
\text { effect } \\
\text { size }\end{array}$ & Decision \\
\hline H1 & PBS $\rightarrow$ OT & 0.148 & 0.073 & $2.035^{*}$ & 0.030 & 0.267 & 0.016 & Supported \\
H2 & PLS $\rightarrow$ OT & -0.059 & 0.070 & 0.839 & -0.181 & 0.051 & 0.003 & Not supported \\
H3 & PRS $\rightarrow$ OT & 0.245 & 0.075 & $3.266^{* * *}$ & 0.119 & 0.365 & 0.043 & Supported \\
H4 $\quad$ PSS $\rightarrow$ OT & 0.278 & 0.067 & $4.166^{* * *}$ & 0.153 & 0.375 & 0.063 & Supported \\
\hline Note. $p<0.05^{*}, p<0.01^{* *}, p<0.001^{* * *}$ & & & & & &
\end{tabular}


The coefficient of determination of organisational trust was $29.2 \%$ and it indicates that the four dimensions of pay satisfaction explained $29.2 \%$ of the variance in organisational trust. To assess predictive relevance, we inspected the cross-validated redundancy and the score was 0.171 , which was above the threshold of zero. Therefore, the model has predictive relevance.

\section{Structural model robustness check}

To complement the standard structural model assessment, we checked for the robustness of the structural model by assessing non-linear effects, endogeneity, and unobserved heterogeneity, following the approach used by Sarstedt et al. (2019) and Svensson et al. (2018). In this paper, we highlighted the structural model robustness checks.

\section{Nonlinear effects}

We followed the two steps involved to assess non-linearity in the model (Sarstedt et al., 2019; Svensson et al., 2018). First, we ran the Ramsey's RESET test in SPSS using the standardised latent variable scores extracted from SmartPLS. The partial regression of organisational trust on pay benefit satisfaction, pay level satisfaction, pay raise satisfaction, and pay structure and administration satisfaction was not significant $(\mathrm{F}$ change $=0.420, \mathrm{p}=0.657)$. Next, we assessed the quadratic model in SmartPLS 3 by creating the quadratic effects for each of the independent variables. Using bootstrapping with 5,000 resampling, we found the quadratic effects for each of the independent variables were not significant, as shown in Table 5 . Thus, the linear effects model was robust.

Table 5: Assessment of nonlinear effects

\begin{tabular}{lcccc}
\hline Quadratic effect & Beta & $\boldsymbol{t}$ value & $\boldsymbol{f}^{\boldsymbol{2}}$ & Ramsey's RESET \\
\hline $\mathrm{PBS}^{2} \rightarrow$ OT & -0.008 & 0.218 & 0.000 & $F(2,299)=0.420, p=0.657$ \\
$\mathrm{PLS}^{2} \rightarrow$ OT & -0.002 & 0.044 & 0.000 & \\
$\mathrm{PRS}^{2} \rightarrow$ OT & -0.015 & 0.346 & 0.000 & \\
$\mathrm{PSS}^{2} \rightarrow$ OT & 0.036 & 1.060 & 0.004 & \\
\hline
\end{tabular}

\section{Endogeneity}

Before we assessed endogeneity, we ran the Kolmogorov-Smirnov with Lilliefors corrections for all of the variables on the $\mathrm{R}$ software by adapting the $\mathrm{R}$ codes from Hult et al. (2018) using the standardised latent variable scores extracted from SmartPLS. The result of the R software showed that they were all significant, and therefore, none of the independent variables were normally distributed. Therefore, we proceed with Park and Gupta's (2012) Gaussian copula approach.

Again, we adapted the R codes from Hult et al. (2018) to run the Gaussian copula in the R software. As shown in Table 6, only the Gaussian copulas for pay structure and administration satisfaction were significant. It may indicate that endogeneity was an issue involving pay structure and administration satisfaction only.

\section{Unobserved heterogeneity}

To identify unobserved heterogeneity, we ran the finite mixture PLS (FIMIX-PLS) procedure (Matthew, Sarstedt, Hair, \& Ringle, 2016; Sarstedt et al., 2019). Additionally, we relied on the G*Power software (Faul et al., 2009) to compute the minimum sample size. The minimum sample size computed was 85 with the assumption of 0.15 effect size, $80 \%$ power and four independent variables. With a minimum sample size of 85 against 306 samples collected, it allows a maximum of three segments. Therefore, we reran FIMIX PLS up to three segments.

The results, shown in Table 7, revealed that Akaike information criterion with factor 4 (AIC4), Bayesian information criterion (BIC), consistent AIC (CAIC), Hannan-Quinn criterion (HQ), and minimum description length with factor 5 (MDL5) indicated a one-segment solution whereas both 
Akaike information criterion (AIC) and Akaike information criterion with factor 3 (AIC3) indicated a three-segment solution. Since AIC tends to overestimate the segments (Matthew et al., 2016), it indicated that the number of segments should be lower than three. According to Sarstedt, Becker, Ringle, and Schwaiger (2011) and Sarstedt, Ringle, and Hair (2017), both AIC3 and CAIC should be assessed together. However, both AIC3 and CAIC pointed to a conflicting result. Nevertheless, since the four best performing criteria, which are AIC4, BIC, CAIC, and HQ (Sarstedt et al., 2011), pointed to a one-segment solution; it showed that only one segment should suffice.

We also assessed the relative segment sizes and Table 8 shows that selecting more than two segments was not reasonable. For an example, if a two-segment solution was chosen, Segment 2 consists of only $17.5 \%$ (54 observations out of 306 observations). This would be too small a sample to warrant a valid analysis, given the minimum sample size computed was 85. Again, it indicated that a one-segment solution would suffice. It therefore shows that unobserved heterogeneity was unlikely to be an issue in this model and thus indicated the structural robustness of this model.

The measurement model has shown to satisfy the convergent and discriminant validity. Regarding the structural model robustness checks, which assessed the non-linear effects, endogeneity, and unobserved heterogeneity, it can be concluded that the structural model was robust with the exception of the endogeneity issue surrounding pay structure and administration satisfaction. It indicates the possibility of pay structure and administration satisfaction being endogenous.

Table 6: Assessment of endogeneity test using the Gaussian copula approach

\begin{tabular}{|c|c|c|c|}
\hline Gaussian copulas test & Construct & Beta & $t$ value \\
\hline Model 1 (endogenous variables; PLS) & CPLS & -0.062 & 0.547 \\
\hline Model 2 (endogenous variables; PBS) & CPBS & 0.009 & 0.085 \\
\hline Model 3 (endogenous variables; PRS) & CPRS & 0.026 & 0.207 \\
\hline Model 4 (endogenous variables; PSS) & CPSS & 0.500 & $1.996 *$ \\
\hline \multirow[t]{2}{*}{ Model 5 (endogenous variables; PBS and PLS) } & CPBS & 0.026 & 0.237 \\
\hline & CPLS & -0.007 & 0.589 \\
\hline \multirow[t]{2}{*}{ Model 6 (endogenous variables; PBS and PRS) } & CPBS & -0.005 & 0.038 \\
\hline & CPRS & 0.030 & 0.192 \\
\hline \multirow[t]{2}{*}{ Model 7 (endogenous variables; PBS and PSS) } & CPBS & -0.022 & 0.210 \\
\hline & CPSS & 0.497 & $2.002 *$ \\
\hline \multirow[t]{2}{*}{ Model 8 (endogenous variables; PLS and PRS) } & CPLS & -0.073 & 0.021 \\
\hline & CPRS & 0.047 & 0.047 \\
\hline \multirow[t]{2}{*}{ Model 9 (endogenous variables; PLS and PSS) } & CPLS & -0.092 & 0.808 \\
\hline & CPSS & 0.515 & $2.081 *$ \\
\hline \multirow[t]{2}{*}{ Model 10 (endogenous variables; PRS and PSS) } & CPRS & 0.014 & 0.107 \\
\hline & CPSS & 0.488 & $1.985 *$ \\
\hline \multirow[t]{3}{*}{ Model 11 (endogenous variables; PBS, PLS, and PRS) } & CPBS & 0.007 & 0.057 \\
\hline & CPLS & -0.074 & 0.619 \\
\hline & CPRS & 0.042 & 0.272 \\
\hline \multirow[t]{3}{*}{ Model 12 (endogenous variables; PBS, PLS, and PSS) } & CPBS & -0.001 & 0.008 \\
\hline & CPLS & -0.092 & 0.778 \\
\hline & CPSS & 0.515 & $2.063 *$ \\
\hline \multirow[t]{3}{*}{ Model 13 (endogenous variables; PLS, PRS, and PSS) } & CPLS & -0.102 & 0.408 \\
\hline & CPRS & 0.041 & 0.131 \\
\hline & CPSS & 0.513 & $2.071 *$ \\
\hline \multirow{4}{*}{$\begin{array}{l}\text { Model } 14 \text { (endogenous variables; PBS, PLS, PRS, and } \\
\text { PSS) }\end{array}$} & CPBS & -0.027 & 0.834 \\
\hline & CPLS & -0.098 & 0.412 \\
\hline & CPRS & 0.059 & 0.704 \\
\hline & CPSS & 0.520 & $2.077 *$ \\
\hline
\end{tabular}

Note: $\mathrm{C}$ indicates the copula term in the model; $\mathrm{p}<0.05^{*}$ 
Table 7: Fit indices for one to three segments

\begin{tabular}{lccc}
\hline Criteria & \multicolumn{3}{c}{ Number of segments } \\
\cline { 2 - 4 } & 1 & 2 & 3 \\
\hline AIC & 772.712 & 766.593 & $\mathbf{7 5 9 . 5 7 2}$ \\
AIC3 & 777.712 & 777.593 & $\mathbf{7 7 6 . 5 7 2}$ \\
AIC4 & $\mathbf{7 8 2 . 7 1 2}$ & 788.593 & 793.572 \\
BIC & $\mathbf{7 9 1 . 3 3 0}$ & 807.552 & 822.873 \\
CAIC & $\mathbf{7 9 6 . 3 3 0}$ & 818.552 & 839.873 \\
HQ & $\mathbf{7 8 0 . 1 5 8}$ & 782.974 & 784.888 \\
MDL & $\mathbf{9 0 5 . 8 0 2}$ & $1,059.390$ & $1,212.077$ \\
LnL & -381.356 & -372.296 & $\mathbf{- 3 6 2 . 7 8 6}$ \\
EN & N.A. & 0.573 & $\mathbf{0 . 7 0 0}$ \\
NFI & N.A. & 0.598 & $\mathbf{0 . 6 6 8}$ \\
NEC & N.A. & 130.732 & $\mathbf{9 1 . 6 8 4}$ \\
\hline
\end{tabular}

Note: AIC = Akaike information criterion; AIC3 = modified AIC with factor 3; AIC4 = modified AIC with factor $4 ;$ BIC $=$ Bayesian information criterion; CAIC = consistent $\mathrm{AIC} ; \mathrm{HQ}=$ Hannan Quinn criterion; MDL5 = minimum description length with factor $5, \mathrm{LnL}=\log$ Likelihood, $\mathrm{EN}=$ entropy statistic, $\mathrm{NFI}=$ non-fuzzy index, NEC $=$ normalised entropy criterion. Numbers in bold indicate the best outcome per segment retention criterion.

Table 8: Relative segment sizes $(\mathrm{N}=306)$

\begin{tabular}{cccc}
\hline Number of segments & Segment 1 & Segment 2 & Segment 3 \\
\hline 1 & 1.000 & & \\
2 & 0.825 & 0.175 & 0.039 \\
\hline
\end{tabular}

Note: Each row shows the relative segment sizes in declining order per solution.

\section{Importance performance map analysis (IPMA)}

To complement the PLS-SEM analysis, importance-performance map analysis (IPMA) was carried out to analyse the importance and performance of each dimension of pay satisfaction against organisational trust. Through IPMA, low performing but important variables can be identified for improvement purpose. The standardised total effects (importance) and the standardised latent variable scores (performance) are shown in Table 9 and Figure 2 below.

Table 9: Importance and performance of IPMA

\begin{tabular}{lcc}
\hline Variables & Total effects (Importance) & $\begin{array}{c}\text { Latent variable scores } \\
\text { (Performance) }\end{array}$ \\
\hline PBS & 0.148 & 57.993 \\
PLS & 0.059 & 54.592 \\
PRS & 0.245 & 56.110 \\
PSS & 0.278 & 52.563 \\
\hline
\end{tabular}

In terms of importance, pay structure and administration satisfaction (0.278) scored the highest followed by pay raise satisfaction (0.245), pay benefit satisfaction (0.148), and lastly pay level satisfaction (0.059). In terms of performance, pay benefit satisfaction (57.993) scored the highest, followed by pay raise satisfaction (56.110), pay level satisfaction (54.592), and lastly pay structure and administration satisfaction (52.563). It indicated that organisations in Malaysia should concentrate on pay structure and administration satisfaction because it performed poorly compared to other factors but yet it is the most important factor to gain trust from employees. Hence, an improvement is needed to turn pay structure and administration into a better state of satisfaction for employees. 


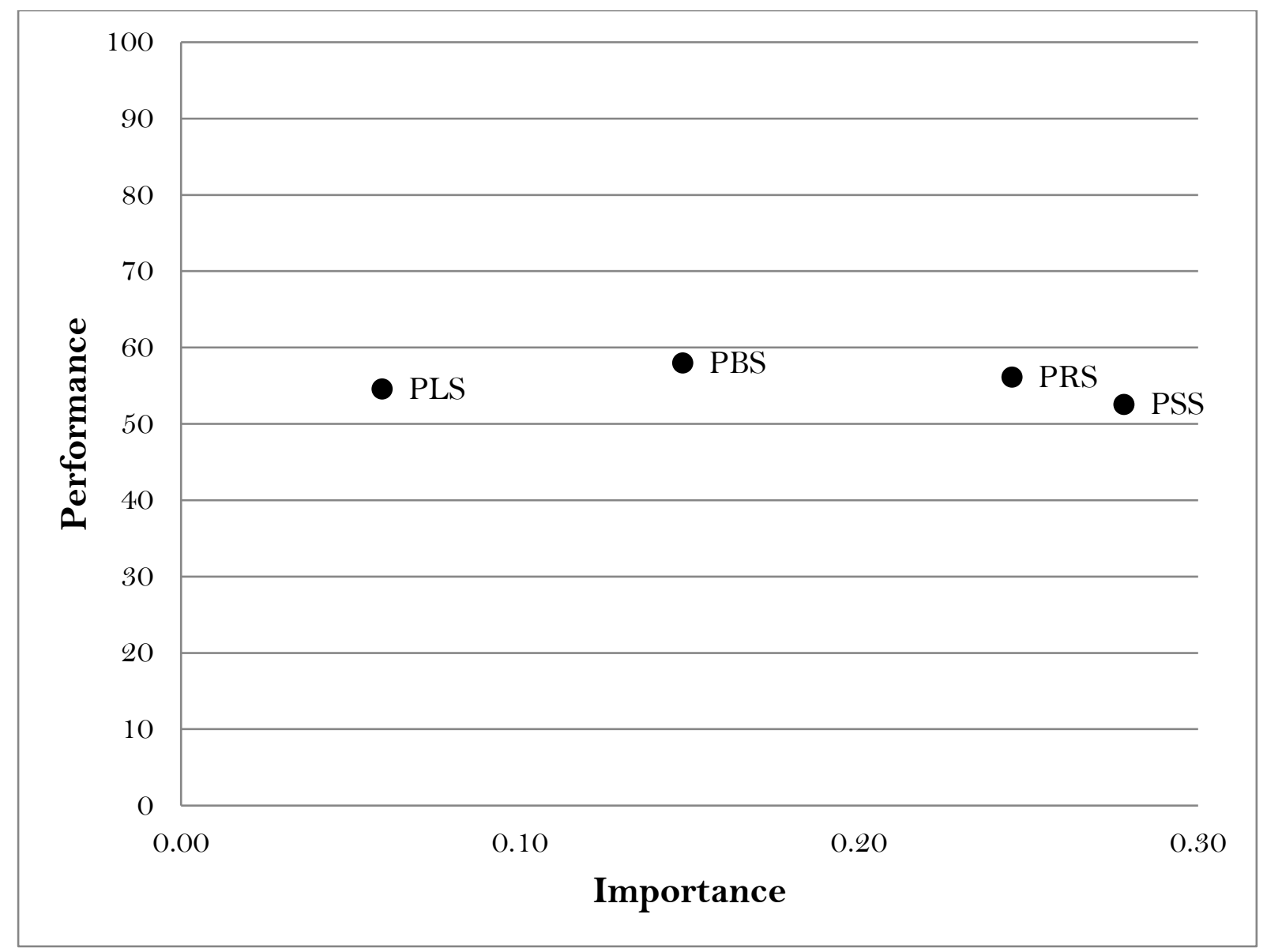

Figure 2: IPMA chart

\section{DISCUSSION}

This paper has demonstrated how social exchange theory and equity theory explain the relationship among the four dimensions of pay satisfaction and organisational trust.

Specifically, pay benefit satisfaction, pay raise satisfaction, and pay structure and administration satisfaction have been shown to have positive relationships with organisational trust. The current findings draw parallel with the study by Moon et al. (2014) which showed that pay benefit satisfaction and pay system satisfaction were positively related to trust.

However, pay level satisfaction was not found to be related with organisational trust, which also drew parallel with the study by Moon et al. (2014). Nevertheless, this study adds to the literature on pay satisfaction demonstrating that pay benefit satisfaction, pay raise satisfaction, and pay structure and administration satisfaction play important roles in eliciting trust from employees. This is very much consistent with the social exchange theory whereby if an employer wishes to gain something from employees, they must offer something in return. Similarly, equity theory explains that employees who perceive that their salary is fair are more likely to bring positive outcomes to organisations, such as higher organisational trust for this instance.

Given that distributive justice was associated with pay level satisfaction (Jawahar \& Stone, 2011), it supported the idea that distributive justice is less interpretable (Van den Bos, Lind, Vermunt, \& Wilke, 1997) and therefore makes pay level satisfaction less satiable compared to the other dimensions of pay satisfaction.

Likewise, since procedural justice was related to pay benefit satisfaction, pay raise satisfaction, and pay structure and administration satisfaction, it supported the idea that procedural justice is more 
interpretable compared to distributive justice (Van den Bos et al., 1997). Since salary is confidential, employees find it hard to compare with each other and is thus less interpretable and less comparable. That explains why pay level satisfaction is not related to organisational trust. On the other hand, procedures relating to salary are usually made known to employees which therefore makes it easier for comparison and interpretability.

\section{IMPLICATIONS}

\section{Theoretical implications}

The findings are consistent with the social exchange theory (Blau, 1964) and equity theory (Adams, 1965) in explaining how the four dimensions of pay satisfaction influence organisational trust. The measurement model through confirmatory factor analysis also supported the four dimensions of pay satisfaction as forwarded by Heneman and Schwab (1985).

Most importantly, this study provides empirical support that pay benefit satisfaction, pay raise satisfaction, and pay structure and administration satisfaction are positively related to organisational trust. Overall, when employees are satisfied with their benefit, pay raise, and how their pay is administered, they will reciprocate by trusting the organisation; thus, supporting the explanation of the social exchange theory.

\section{Practical implications}

Both the effect sizes and the IPMA results showed that pay structure and administration satisfaction was the most important factor to gain trust from employees on the organisation, followed by pay raise satisfaction, pay benefit satisfaction, and lastly pay level satisfaction. This signals to policy makers in organisations to pay utmost attention to pay structure and administration satisfaction to develop trust in organisation among employees. Employers should develop consistent pay policies that reflect fair adjustments to the employees' actual salary and consequently, communicate those policies to the employees (Khokhar \& Zia-ur-Rehman, 2014). Researchers (Jung \& Yoon, 2015; Till \& Karren, 2011) have already echoed the importance of having employers to demonstrate to employees the transparency of the pay structure and such information is accessible to employees. When an employer has a track record of upholding procedural justice, it serves as an indicator of their trustworthiness (Graso, Jiang, Probst, \& Benson, 2014).

The results of this study favour organisations because it is less costly to modify the structure and administration of the pay system (Lambert, Hogan, \& Cheeseman, 2013). Therefore, organisations should focus on implementing fair procedures that could also generate higher satisfaction with the pay structure and administration, pay raise, and benefit (Jawahar \& Stone, 2011).

\section{LIMITATIONS AND FUTURE SUGGESTIONS}

As in any studies, there are limitations in this research. First of all, the samples collected in this study were through snowball sampling, which is a form of non-probability sampling. Therefore, it limits the generalisability of the results. Future studies may consider restricting the samples to a specific occupation to control the homogeneity of the samples.

Secondly, data were collected at a single point of time which render its inability to establish causality between pay satisfaction and trust. Although the social exchange theory assists in explaining the causal effects, future studies may consider using experimental field research or longitudinal study to empirically determine the causal effects.

Thirdly, the structural model robustness checks indicated that pay structure and administration satisfaction was potentially endogenous in its relationship with organisational trust which was not addressed in this study. Therefore, there are omitted variables that could potentially affect the 
variables in the current study. Future studies may include organisational justice variables that have been known to affect both pay satisfaction and trust (Jawahar \& Stone, 2011; Jiang et al., 2015; Folger \& Konovsky, 1989; Ogbonnaya \& Daniels, 2017; Tekleab et al., 2005). Additionally, future studies may include control variables in relation with trust such as age, gender, educational level, and organisational tenure in line with previous studies (Jiang et al., 2015; Ogbonnaya \& Daniels, 2017; Tan \& Lim, 2009) to address endogeneity issues.

\section{ACKNOWLEDGEMENT}

This paper was earlier presented at the International Symposium of Applied Structural Equation Modeling and Methodological Matters (SASEM 2019).

\section{REFERENCES}

Adams, J. S. (1965). Inequity in social exchange, In L. Berkowitz (Ed.), Advances in experimental psychology (Vol. 2, pp. 267-299). New York, NY: Academic Press.

Ahteela, R., \& Vanhala, M. (2018). HRM bundles and organizational trust. Knowledge and Process Management, 25(2/3), 3-11.

Babin, B. J., Griffin, M., \& Hair, J. F., Jr. (2016). Heresies and sacred cows in scholarly marketing publications. Journal of Business Research, 69, 3133-3138.

Bank Negara Malaysia (2018). Annual Report. Bank Negara Malaysia.

Benjamin, E. (2018). Women call for greater transparency at the workplace, says PwC. The Edgemarkets.com. Retrieved from https://www.theedgemarkets.com/article/women-callgreater-transparency-workplace-says-pwc

Bhave, D. P., Kramer, A., \& Glomb, T. M. (2013). Pay satisfaction and work-family conflict across time. Journal of Organizational Behaviour, 34, 698-713.

Blau, P. M. (1964). Exchange and power in social life. New York: John Wiley \& Sons.

Campbell, J. W., \& Im, T. (2019). Exchange ideology, performance pay, and pay satisfaction: Evidence from South Korean Central. Public Personnel Management, 48, 584-607.

Chan, J S. H., \& Ao, D. C. T. (2018). The mediating effects of job satisfaction and organizational commitment on turnover intention, in the relationships between pay satisfaction and workfamily conflict of casino employees. Journal of Quality Assurance in Hospitality \& Tourism, 20, 206-229.

Cloutier, J., Morin, D., \& Renaud, S. (2013). How does variable pay relate to pay satisfaction among Canadian workers? International Journal of Manpower, 34, 465-485.

Faul, F., Erdfelder, E., Buchner, A., \& Lang, A. G. (2009). Statistical power analyses using G*Power 3.1: Tests for correlation and regression analyses. Behaviour Research Methods, 41, 1149-1160.

Folger, R., \& Konovsky, M. A. (1989). Effects of procedural and distributive justice on reactions to pay raise decisions. Academy of Management Journal, 32, 115-130.

Gold, A. H., Malhotra, A., \& Segars, A. H. (2001). Knowledge management: an organizational capabilities perspective. Journal of Management Information Systems, 18, 185-214.

Graso, M., Jiang, L., Probst, T. M., \& Benson, W. L. (2014). Cross-level effects of procedural justice perceptions on faculty trust. Journal of Trust Research, 4, 147-166. 
Hair, J. F., Hult, G. T. M., Ringle, C. M., \& Sarstedt, M. (2017). A primer on partial least squares structural equation modeling (PLS-SEM) (2nd ed.). Thousand Oaks, California: Sage Publication.

Heneman, H. G. III, \& Schwab, D. P. (1985). Pay satisfaction: Its multidimensional nature and measurement. International Journal of Psychology, 20, 129-141.

Hult, G. T. M., Hair, J. F. Jr., Proksch, D., Sarstedt, M., Pinkwart, A., \& Ringle, C. M. (2018).

Addressing endogeneity in international marketing applications of partial least squares structural equation modeling. Journal of International Marketing, 26(3), 1-21.

Jawahar, I. M., \& Stone, T. H. (2011). Fairness perceptions and satisfaction with components of pay satisfaction. Journal of Managerial Psychology, 26, 297-312.

Jiang, Z., Gollan, P. J., \& Brooks, G. (2015). Relationships between organizational justice, organizational trust, and organizational commitment: A cross-cultural study of China, South Korea and Australia. The International Journal of Human Resource Management, 28, 973-1004.

Jobstreet.com (2017). Employee job happiness index 2017. Jobstreet.com

Johnson, D., \& Lake, C. J. (2019). Contingent worker monetary influence work attitudes and behaviour. Personnel Review, 48, 1669-1684.

Jung, H. S., \& Yoon, H. H. (2015). Understanding pay satisfaction: The impacts of pay satisfaction on employees' job engagement and withdrawal in deluxe hotel. International Journal of Hospitality Management, 48, 22-26.

Khokhar, A. M., \& Zia-ur-Rehman, M. (2014). A study of pay satisfaction and work-to-family conflict. Compensation and Benefits Review, 46, 177-187.

Kim, B. J. (2019). Unstable jobs cannot cultivate good organizational citizens: The sequential mediating role of organizational trust and identification. International Journal of Environmental Research and Public Health, 16, 1102-1116.

Lambert, E. G., Hogan, N. L., Barton-Bellessa, S. M., \& Jiang, S. (2012). Examining the relationship between supervisor and management trust and job burnout among correctional staff. Criminal Justice and Behaviour, 39, 938-957.

Mahalingam, E. (2013, February 9). Salary vs job satisfaction. The Star. Retrieved from: https://www.thestar.com.my/business/business-news/2013/02/09/salary-vs-jobsatisfaction/

Matthews, L. M., Sarstedt, M., Hair, J. F., \& Ringle, C. M. (2016). Identifying and treating unobserved heterogeneity with FIMIX-PLS: Part II - A case study. European Business Review, 28, 208-224.

Miceli, M. P., \& Lane, M. C. (1991). Antecedents of pay satisfaction: A review and extension.

In K. Rowland \& J. Ferris (Eds.), Research in personnel and human resources management (pp. 235-309). Greenwich, CT: JAI Press.

Moon, K., Cho, H., Lee, K., \& Oah, S. (2014). Effect of pay satisfaction on organizational commitment: Mediating effect of organizational trust. Korean Journal of Industrial and Organizational Psychology, 27, 585-615.

Ogbonnaya, C., \& Daniels, K. (2017). Does contingent pay encourage positive employee attitudes and intensify work? Human Resource Management Journal, 27, 94-112.

Park, S., \& Gupta, S. (2012). Handling endogenous regressors by joint estimation using copulas. Marketing Science, 31, 567-586. 
R Core Team (2019). R: A language and environment for statistical computing. R Foundation for Statistical Computing, Vienna, Austria. URL https://www.R-project.org/.

Ren, T., Fang, R., \& Yang, Z. (2017). The impact of pay-for-performance perception and pay level satisfaction on employee work attitudes and extra-role behaviours: An investigation of moderating effects. Journal of Chinese Human Resource Management, 8, 94-113.

Ringle, C. M., Wende, S., \& Becker, J. M. (2015). SmartPLS 3 [Computer software]. Retrieved from http://www.smartpls.com

Robinson, S. L. (1996). Trust and breach of psychological contrast. Administrative Science Quarterly, 41, 574-599.

Sarstedt, M., Becker, J. M., Ringle, C. M. \& Schwaiger, M. (2011). Uncovering and treating unobserved heterogeneity with FIMIX-PLS: which model selection criterion provides an appropriate number of segments? Schmalenbach Business Review, 63(1), 34-62.

Sarstedt, M., Ringle, C. M., Cheah, J. H., Ting, H., Moisescu, O. I., \& Radomir, L. (2019). Structural model robustness checks in PLS-SEM. Tourism Economics, doi: 10.1177/1354816618823921.

Sarstedt, M., Ringle, C. M., \& Hair, J. F. (2017). Treating unobserved heterogeneity in PLS-SEM: A multi-method approach. In H. Latan, \& R. Noonan (Eds.), Partial least squares path modeling: Basic concepts, methodological issues and applications (pp. 197-217). Switzerland: Springer.

Singh, P., \& Loncar, N. (2010). Pay satisfaction, job satisfaction, and turnover intent. Industrial Relations, 65, 470-490.

Svensson, G., Ferro, C., Høgevold, N., Padin, C., Varela, J. C. S., \& Sarstedt, M. (2018). Framing the triple bottom line approach: direct and mediation effects between economic, social and environmental elements. Journal of Cleaner Production, 197, 972-991.

Tabachnick, B. G., \& Fidell, L. S. (2013). Using multivariate statistics (6th ed.). Pearson: New Jersey.

Tan, H. H., \& Lim, A. K. H. (2009). Trust in coworkers and trust in organizations. The Journal of Psychology, 143, 45-66.

Tekleab, A. G., Bartol, K. M., \& Liu, W. (2005). Is it pay levels or pay raises that matter to fairness and turnover? Journal of Organizational Behavior, 26, 899-92 1.

Till, R. E., \& Karren, R. (2011). Organizational justice perceptions and pay level satisfaction. Journal of Managerial Psychology, 26, 42-57.

Treuren, G. J. M., \& Frankish, E. (2014). The impact of pay understanding on pay satisfaction and retention: Salary sacrifice understanding in the not-for-profit sector. Journal of Industrial Relations, 56, 103-122.

Van den Bos, K., Lind, E. A., Vermunt, R., \& Wilke, H. A. M. (1997). How do I judge my outcome when I do not know the outcome of others? The psychology of the fair process effect. Journal of Personality and Social Psychology, 72, 1034-1046.

Van Sonderen, E., Sanderman, R., \& Coyne, J. C. (2013). Ineffectiveness of reverse wording of questionnaire items: Let's learn from cows in the rain. PLoS One, 8(7), 1-7.

Wang, E., Hu, H., Mao, S., \& Liu, H. (2019). Intrinsic motivation and turnover intention among geriatric nurses employed in nursing homes: The roles of job burnout and pay satisfaction. Contemporary Nurse, 55, 195-210.

Williams, M. L., McDaniel, M. A., \& Ford, L. R. (2007). Understanding multiple dimensions of compensation satisfaction. Journal of Business and Psychology, 21, 429-459. 
Zheng, S., Wang, Z., \& Song, S. (2014). Pay satisfaction of employees: A case study of a state-owned science institute of China. Social Indicators Research, 119, 1219-1231.

\section{APPENDIX}

\begin{tabular}{lll}
\hline Variable & Item & Measurement item \\
\hline Pay benefit & PBS1 & My benefit package. \\
satisfaction & PBS2 & Total amount of my benefits. \\
& PBS3 & The value of my benefits. \\
Pay level & PBS4 & The number of benefits I receive. \\
satisfaction & PLS1 & My take-home salary \\
& PLS2 & My current salary. \\
Pay raise & PLS3 & My overall level of salary. \\
satisfaction & PLS4 & Total amount of my current salary. \\
& PRS1 & My most recent salary raise. \\
Pay structure & PRS3 & How my supervisor influence my salary. \\
and & PRS4 & How my company determines my salary raises \\
administration & PSS1 & My company's pay policies \\
satisfaction & PSS2 & Important information given to me on salary issues. \\
& PSS3 & How other employees are paid in my company. \\
Organisational & PSS4 & Consistency of my company's pay policies. \\
trust & PSS5 & Differences in salary among employees in my company. \\
& PSS6 & How the company determines salary. \\
& OT1 & I believe my employer has high morals. \\
& OT2 & I can expect my employer to treat me consistently and predictably. \\
& OT3 & My employer is not always honest and truthful. (Reversed) \\
& OT4 & In general, I believe my employer's motives and intentions are good. \\
& OT5 & I do not think my employer treats me fairly. (Reversed) \\
& OT6 & My employer is open and frank with me. \\
& OT7 & I do not fully trust my employer. (Reversed) \\
\hline
\end{tabular}

